\section{Ciliary body naevus}

\begin{abstract}
Purpose To describe clinical, ultrasound biomicroscopy (UBM), and histopathologic characteristics of benign melanocytic tumors of the ciliary body.

Design Consecutive case series. Methods Six patients with a pigmented ciliary body tumour underwent complete ophthalmic examination and UBM, with histopathologic examination carried out on three cases.

Results Six patients presented with a pigmented iridociliary mass, with central displacement of iris root. UBM revealed a stromal mass arising in pars plicata and/or pars plana in all six with a cyst in three cases (intrinsic $=1$ and extrinsic $=2$ ). Iridocyclectomy was performed because of documented growth in three cases, and all three cases proved to be ciliary body spindle-cell naevus. The other three patients have remained stable.

Conclusions On clinical basis and with available ancillary studies, ciliary body naevi cannot be reliably differentiated from ciliary body melanocytoma and ciliary body melanoma. Even with clinically documented growth, the lesions may prove to be ciliary body naevi. Eye (2007) 21, 1528-1530; doi:10.1038/sj.eye.6702622; published online 20 October 2006
\end{abstract}

Department of Ophthalmic Oncology, Cole Eye Institute, Cleveland Clinic Foundation, Cleveland, $\mathrm{OH}$, USA

Correspondence: AD Singh,

Cole Eye Institute,

Cleveland Clinic

Foundation,

9500 Euclid Avenue, Cleveland, OH 44195, USA

Tel: + 1216445 9479;

Fax: + 12164452226

E-mail: singha@ccf.org

Received: 21 May 2006 Accepted in revised form: 4 September 2006

Published online:

20 October 2006

Presented at ARVO 2006

The authors have no financial or proprietary interest in this paper
Keywords: ciliary body mass; ciliary body naevus; spindle-cell naevus

Although iris and choroidal naevi are well characterized, ciliary body naevi have rarely been described in the literature. ${ }^{1-4}$ Moreover, due to their obscure location, their clinical features are lacking. Herein, we report six cases of ciliary body naevi and provide detailed clinical, echographic, and pathological characteristics of two representative cases.

\section{Case reports}

\section{Case 1}

A 59-year-old Caucasian female was noted to have an 'iris' lesion OS in 1982. The lesion had remained stable to observation every 1-2 years by her ophthalmologist. In March 2004, increased size was noted by the patient and confirmed by the ophthalmologist. Patient also complained of blurred vision OS, fluctuating over the past few months. Past medical or other ocular history were negative. Visual acuity was 20/20 OD, 20/30 OS. Intraocular pressures, pupils, extraocular motions, and confrontational visual fields were normal. Anterior segment examination of the right eye and fundus examination of both eyes were normal. Anterior segment examination of the left eye revealed a pigmented $4 \mathrm{~mm}$ iris root mass at 7-8 o'clock position displacing the iris root anteriorly (Figure 1a). A sentinel vessel, pigment dusting, and a sectoral cataract were also present. Ultrasound biomicroscopy (UBM) revealed a $4 \times 4 \times 2.5 \mathrm{~mm}$ solid lesion of the pars plicata region with extension into the iris root

(Figure 1b). An intrinsic cystic space was also observed.

Given the history of growth of the lesion and its location, iridocyclectomy was performed, due to concern of possible melanoma. The histopathology of the lesion revealed a benign pigmented, spindle-cell naevus of the ciliary body (Figure 1c).

\section{Case 4}

A 51-year-old Caucasian female was referred to the Department of Ophthalmic Oncology at the Cole Eye Institute for further evaluation of an iridociliary mass found on a routine examination. A dilated ophthalmic examination 1 year earlier was apparently normal. On examination, visual acuity was $20 / 20$ OU with correction. The intraocular pressures and pupils were normal. There was no melanocytosis or heterochromia. The iris was blue in colour. Anterior segment examination of the right eye and fundus examination of both eyes were unremarkable. Slit-lamp examination of the left eye showed an area of abnormal pigmentation of the iris root at about the 8:30 o'clock position with iris stromal folds central to the lesion. The lesion corresponded in location to a sectoral 
cataract, which raised the possibility of a ciliary body mass. After dilatation and even gonioscopic evaluation, the ciliary body appeared to be normal. However, on
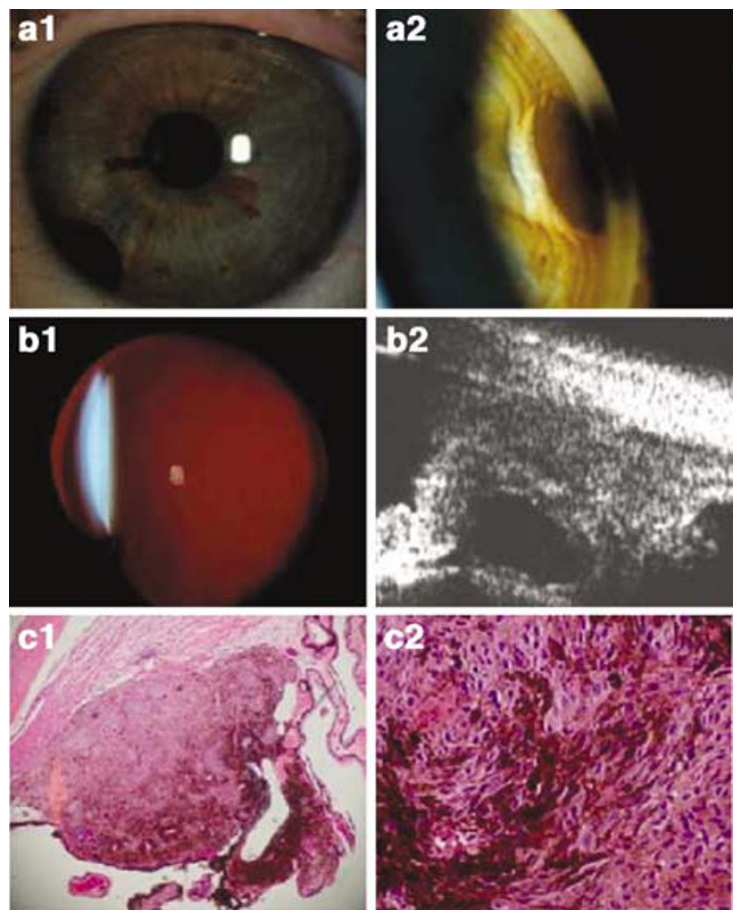

UBM, an ill-defined, solid, anterior ciliary mass was identified, confined to the pars plicata region and measuring $0.9 \times 0.9 \times 1.4 \mathrm{~mm}$. Following detailed discussion with the patient over continued observation versus removal of the lesion by iridocyclectomy, the patient elected for continued observation. Follow-up examination 18 months later has shown no changes in visual acuity, sectoral cataract, or UBM measurements.

\section{Comment}

Unlike choroidal or iris naevi, ciliary body naevi have rarely been reported in the literature. ${ }^{1-4}$ Choroidal naevus is defined as having thickness less than $1 \mathrm{~mm}$ and basal diameter less than $5 \mathrm{~mm}$; however, there are no

\footnotetext{
Figure 1 External appearance of a pigmented iridociliary tumor in 7-8 o'clock position along with a sentinel vessel (a1). Gonioscopy showed the iridociliary lesion displacing the iris root anteriorly (a2). Slit-lamp examination showing a sectoral cataract (b1). UBM revealing a $4 \times 4 \times 2.5 \mathrm{~mm}$ solid lesion of the ciliary body with large cystic space (b2). Histopathology of lesion following iridocyclectomy (c1) revealed a benign pigmented naevus of the ciliary body, with predominantly small, spindled cells (c2).
}

Table 1 Six patients with ciliary body naevi

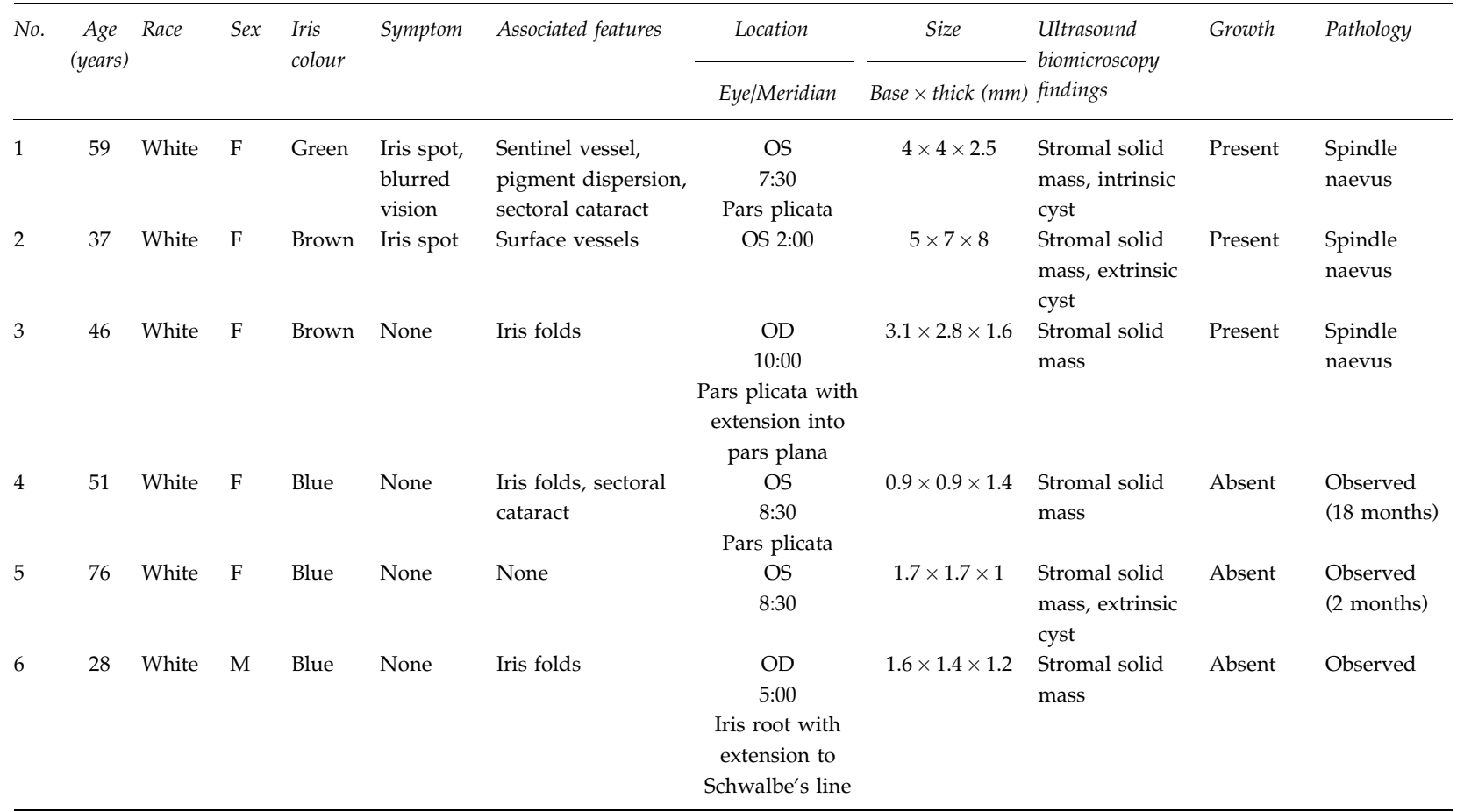

$\mathrm{OD}=$ right eye $\mathrm{OS}=$ left eye; $\mathrm{F}=$ female; $\mathrm{M}=$ male.

All had a pigmented iridociliary mass with central displacement of iris root in all six. With gonioscopy, only the anterior aspect of the lesion was visualized. Ultrasound biomicroscopy revealed a solid stromal mass arising in pars plicata and/or pars plana in all six cases with a cyst in three cases (intrinsic $=1$ and extrinsic $=2$ ). Cases 1 and 2 complained of an 'iris spot', whereas the others were found on routine examination. The tumour thickness ranged from 1 to $8 \mathrm{~mm}$. 
available size criteria for ciliary body naevi. Moreover, the data on ciliary body spindle-cell naevi is lacking as they are usually detected only on retrospective pathological studies.

Both benign and malignant tumours of the ciliary body may be pigmented or nonpigmented, undergo necrosis, cause secondary iritis or cataract, or increase intraocular pressure by invading the angle. Similarly, melanoma and naevus can demonstrate slow growth and locally aggressive behaviour. ${ }^{1,5}$ Therefore, tumour growth or recent onset cannot be relied upon as a differentiating factor, as demonstrated by our cases. Certain features, such as prominent episcleral sentinel vessels, multilobulation of the mass, and ultrasound graphic hollowness with intrinsic vascular pulsations, suggest ciliary body melanoma. However, more often, definite diagnosis can only be made by histopathology. Harbour et $a l^{6}$ reported that features suggesting malignant melanomas of iris were largest basal tumour diameter greater than $3 \mathrm{~mm}$, presence of pigment dispersion, prominent tumour vascularity, elevated intraocular pressure, and tumour-related ocular symptoms. Similar differentiating features for ciliary body melanomas are not known. The ciliary body tumour thickness in our cases ranged from 1 to $8 \mathrm{~mm}$ (Table 1 ).

Many ophthalmologists choose to observe pigmented lesions of the ciliary body. However, given the above reasons, others favour iridocyclectomy over observation. Before surgery, a biopsy specimen of an episcleral or scleral pigmentation, or cytologic examination of a fineneedle aspiration biopsy may be helpful in establishing the diagnosis. However, although the detection of malignant cells from a fine-needle biopsy procedure may confirm the clinical diagnosis of melanoma, the retrieval of benign cells does not exclude the possibility of malignant cells in portions of the tumour that were not sampled. ${ }^{7}$
In conclusion, ciliary body naevi do exist and may be more common than previously thought. They are usually missed secondary to their hidden location, but UBM can be a useful diagnostic tool. Clinical features of ciliary body naevi are not distinctive enough to distinguish them from melanoma with certainty. Patient's concerns, in addition to clinical features, presence or absence of growth, and surgeon's preference, usually determine the appropriate management. Iridocyclectomy may be performed on suspicious ciliary body lesions with good visual prognosis (Table 1), although close observation is a reasonable alternative.

\section{References}

1 Li B, Sun X, Zheng B, Li L, Chen C. The histogenesis, clinical features and histopathological analysis on 52 cases of ciliary body neoplasms. Zhonghua Yan Ke Za Zhi 2000; 36: 250-254.

2 Gordon E. Nevus of the choroid and pars plana. Surv Ophthalmol 1963; 123: 507-511.

3 Naumann G, Yanoff M, Zimmerman LE. Histogenesis of malignant melanomas of the uvea. Arch Ophthalmol 1966; 76: 784-796.

4 Hale PN, Allen RA, Straatsma BR. Benign melanomas (nevi) of the choroid and ciliary body. Arch Ophthalmol 1965; 74: 532-538.

5 Frangieh GT, Baba FE, Traboulsi E, Green WR. Melanocytoma of the ciliary body: presentation of four cases and review of nineteen reports. Surv Ophthalmol 1985; 29: 328-334.

6 Harbour JW, Augsburger JJ, Eagle Jr RC. Initial management and follow-up of melanocytic iris tumors. Ophthalmology 1995; 102: 1987-1993.

7 Rummelt V, Naumann GOH, Folberg R, Weingeist TA. Surgical management of melanocytoma of the ciliary body with extrascleral extension. Am J Ophthalmol 1994; 117: 169-176. 